\title{
Green synthesis, characterization and antibacterial activity of copper nanoparticles using $L$-ascorbic acid as a reducing agent
}

\author{
Deneke Shamebo Menamo ${ }^{1}$, Delele Worku Ayele ${ }^{2, *}$, Mirtachew Tihar Ali ${ }^{1}$ \\ ${ }^{1}$ Department of Chemistry, College of Science, Bahir Dar University, P. O. Box 79, Bahir Dar, Ethiopia \\ ${ }^{1}$ Department of Chemistry, College of Science, Bahir Dar University, P. O. Box 79, Bahir Dar, Ethiopia \\ ${ }^{2}$ Department of Material Science and Eng., College of Science, Bahir Dar University, P. O. Box 79, Bahir Dar, Ethiopia
}

\begin{abstract}
Synthesis of $\mathrm{Cu}$ nanoparticles using chemical route offers a competitive alternative approach over the common biological and physical procedures. In this study, simple, economical, convenient and environmentally-friendly chemical reduction technique was used for the production of $\mathrm{Cu}$ nanoparticles from $\mathrm{CuCl}_{2} \cdot 2 \mathrm{H}_{2} \mathrm{O}$ solution using $\mathrm{L}$-ascorbic acid as reducing and capping agent. The effects of concentration of precursor salt and ascorbic acid, reaction time and reaction temperature on the synthesis of $\mathrm{Cu}$ nanoparticles were studied. The optical properties of the synthesized $\mathrm{Cu}$ nanoparticles were characterized by UV-Vis Spectroscopy while the crystallinity of synthesized $\mathrm{Cu}$ nanoparticles was verified with the help of X-ray diffraction analysis. The antimicrobial activity of $\mathrm{Cu}$ nanoparticles was determined by Agar disc diffusion method against some selected species of bacteria: two gram positive (Staphylococcus aureus, Streptococcus pyogenes) and two gram negative (Escherichia coli, Pseudomonas aeruginosa). The UV-Vis spectrum of solution of $\mathrm{Cu}$ nanoparticles showed a characteristic peak at $423 \mathrm{~nm}$ that confirms the preparation of Copper nanoparticles. Moreover, FT-IR spectroscopy was performed to detect the binding effect of ascorbic acid on $\mathrm{Cu}$ nanoparticles, and its result indicated that ascorbic acid could prevent oxidation and agglomeration. The findings revealed that $\mathrm{Cu}$ nanoparticles formed at a concentration of $3 \mathrm{mM} \mathrm{Cu}-$ $\mathrm{Cl}_{2} .2 \mathrm{H}_{2} \mathrm{O}$ solution and $4 \mathrm{mM}$ ascorbic acid exhibited an excellent zone of growth inhibition for both gram-negative and gram-positive bacteria, $16.83 \pm 0.42$ and $15.50 \pm 0.89 \mathrm{~mm}$, respectively.
\end{abstract}

Keywords: - Green synthesis, Copper nanoparticles, Chemical reduction, Optical properties, Antibacterial activity

DOI: http://dx.doi.org/10.4314/ejst.v10i3.5

\section{INTRODUCTION}

In recent years, metal nanomaterials have received particular attention for their positive impact on improving many economy sectors including consumer products, energy, transportation, cosmetics, pharmaceuticals, antimicrobial agents and agriculture (Shobha et al., 2014). Moreover, the controlled fabrication of metal nanoparticles has impelled nanotechnology into its advancement in today's most promising and popular field of scientific research (Aysha et al., 2015). Among the metal nanoparticles, copper nanoparticles have been paid great interest because of their excellent physical and chemical properties, versatile applications and low cost of preparation (Kruis et al., 1998; Gopinath et al., 2014; Heera et al., 2015). Currently, copper nanoparticles greatly attracted researchers pertaining to their enormous applications, particularly in flexible electronics,

\footnotetext{
*Corresponding author: delelewww@gmail.com

(C) This is an Open Access article distributed under the terms of the Creative Commons Attribution License (http://creativecommons.org/licenses/CC BY4.0).
} 
printing (as a copper ink), nanocircuits due to their good electrical conductivity, catalytic properties along with high biocompatibility and antibacterial properties (Nadejda et al., 2017). Copper nanoparticles have also more applications such as in the form of heat transfer systems, antimicrobial materials, super strong materials, sensors and catalysts (Eastman et al., 2001; Ipsa and Nayak, 2013; Aysha et al., 2015).

In the synthesis of copper nanoparticles, different methods or approaches such as chemical reduction in aqueous solutions, colloidal synthesis with reduction and extraction steps, evaporation and condensation of metal vapor on a cold surface have been employed (Liu et al., 2012; Kathad and Gajera, 2014). Most of these synthesis methods involved with elevated temperatures, inert atmospheres, large amount of surfactants and organic solvents (Appu and Muthukrishnan, 2015). In addition, the preparation and storage of the synthesized copper nanoparticles is quiet challenging due to its high tendency for oxidation (Appu and Muthukrishnan, 2015; Sudhir et al., 2015)

Thus, designing a suitable synthesis strategy can help researchers synthesize high quality copper nanoparticles having controlled properties. In this study, we designed a synthesis method which is simple, economical, temperature controlled, convenient and environmentally friendly for the production of copper nanoparticles from $\mathrm{CuCl}_{2} \cdot 2 \mathrm{H}_{2} \mathrm{O}$ solution using $L$-ascorbic acid for both a reducing and capping agent. The developed synthesis strategy used simple and nontoxic chemicals and reagents. The synthesized copper nanoparticles were characterized by XRD, UVVis spectroscopy and FT-IR spectroscopy. The antibacterial activity of the synthesized copper nanoparticles for the selected bacterial strains was also investigated using Agar disc diffusion method.

\section{EXPERIMENTAL}

\section{Chemicals and Instruments}

$\mathrm{CuCl}_{2} \cdot 2 \mathrm{H}_{2} \mathrm{O}(99.5 \%), L$-ascorbic acid $(99.9 \%)$ and Paraffin Oil were brought from Blulux laboratories Priv. Ltd, (INDIA-121005). Muller Hinton Agar was brought from Shimakyus pure chemicals. All the chemicals were used without further purification. FT-IR spectrometer (AVATAR 330 FT-IR, Thermo Nicolet), double beam Uv-Vis spectrometer (Sanyo Sp 65), XRD (Philips X-ray diffractometer with the scanning $2 \theta$ ranges from $10^{\circ}$ to $80^{\circ}$ ) were used.

\section{Preparation of copper chloride dihydrate} solutions: A $0.08 \mathrm{M}$ stock solution of $\mathrm{CuCl}_{2} \cdot 2 \mathrm{H}_{2} \mathrm{O}$ with distilled water was prepared. Different concentrations of the salt solution $(1 \mathrm{mM}, 2 \mathrm{mM}, 3$ $\mathrm{mM}$ and $4 \mathrm{mM}$ ) were also prepared from the stock solution (Vasudeo et al., 2015).

Preparation of $\boldsymbol{L}$-ascorbic acid solution: A 0.08 $M$ stock solution of $L$-ascorbic acid $\left(\mathrm{C}_{6} \mathrm{H}_{8} \mathrm{O}_{6}\right)$ was prepared by dissolving $14.08 \mathrm{~g}$ of the $L$-ascorbic acid in $1000 \mathrm{ml}$ of distilled water. Different concentrations ( $2 \mathrm{mM}, 4 \mathrm{mM}, 6 \mathrm{mM}$ and $8 \mathrm{mM}$ ) of L-ascorbic acid were prepared from the stock solution of L-ascorbic acid.

Synthesis of copper nanoparticles: The method reported by Umer et al. (2014) with slight modification was used in this study in order to synthesize $\mathrm{Cu}$ nanoparticles. A specified concentration of the solution of $L$-ascorbic acid was mixed drop wise with a specified concentration of the solution of $\mathrm{CuCl}_{2} \cdot 2 \mathrm{H}_{2} \mathrm{O}$ salts by heating and stirring at different reaction temperature and time (45-90 ${ }^{\circ} \mathrm{C}$ and $0-12 \mathrm{hrs}$, respectively), until $\mathrm{Cu}$ 
nanoparticles were formed. In order to study the effects of temperature and concentration of metal salt and $L$-ascorbic acid on the formation copper nanoparticles, the experiment was conducted at different reaction temperature and concentration of the precursors. The as-synthesized precipitates of copper nanoparticles were formed when the reaction was completed. The precipitate of copper nanoparticles was subjected to centrifugation so as to isolate it from the supernatant solution, and then the precipitate was washed twice with distilled water. Finally, the sample was dried, and then it was kept under desiccators to protect it from moisture and apparently from oxidation (Liu et al., 2012).

Antibacterial susceptibility test: The antibacterial assays were performed by standard Agar disc diffusion method against some selected species of bacteria: two gram positive (Staphylococcus aureus, Streptococcus pyogenes) and two gram negative (Escherichia coli, Pseudomonas aeruginosa). Nutrient broth/agar (1g beef extract, $1 \mathrm{~g}$ peptone, $0.5 \mathrm{~g} \mathrm{NaCl}$ ) dissolved in $100 \mathrm{~mL}$ of distilled water was used to cultivate the bacteria. The media was autoclaved, cooled and poured in the petri dishs and kept for 30 minutes for solidification. Four different fresh cultures of inoculums $(100 \mu \mathrm{L})$ were spread on to solidified nutrient agar plates. Sterile paper discs made of Whatman filter paper and the paper discs $(6 \mathrm{~mm}$ in diameter) impregnated with antibiotic solution were placed on the surface of each Mueller Hinton Agar (MHA) plate using a sterile pair of forceps. Sterile paper discs made of Whatman filter paper, $6 \mathrm{~mm}$ diameter, were dipped into $50 \mu \mathrm{L}$ solution of copper nanoparticles. Solution of copper chloride and solution of L-ascorbic acid were placed in each plate including positive control. The cultured agar plates were incubated at $37^{\circ} \mathrm{C}$ for $24 \mathrm{hrs}$. After $24 \mathrm{hrs}$ of incubation, the zone of inhibition growth was investigated. Finally, the plates were incubated aerobically. The bigger the diameter of the inhibition zone, the more susceptible is the microorganism to the antimicrobial agent (EspinelIngroff and Pfaller, 2007).

Characterization: The optical properties of copper nanoparticles were studied by UVvisible spectroscopy using a double beam spectrophotometer (Sanyo Sp 65 UV/Vis spectrophotometer) in the spectral range from 200 $\mathrm{nm}$ to $800 \mathrm{~nm}$. The UV-Vis absorption spectra of all the samples were recorded, and numerical data were plotted in the "Origin 8" software.

The XRD patterns of copper nanoparticles were recorded using Philips X-ray diffractometer with the scanning $2 \theta$ ranges from $10^{\circ}$ to $80^{\circ}$, wherein the radiation employed was copper $\mathrm{K} \alpha$ with a wavelength of $1.54056^{\circ} \mathrm{A}$. The average particle size was determined from the XRD diffractograms of the sample using the Debye-Scherer equation by taking (111) phase of the XRD patterns (Langford and Wilson, 1978; Monshi et al., 2012).

Moreover, FT-IR spectra (AVATAR 330 FT-IR, Thermo Nicolet) analysis in the region of 4000 $\mathrm{cm}^{-1}-400 \mathrm{~cm}^{-1}$ with a resolution of $0.09 \mathrm{~cm}^{-1}$ was used and recorded. FT-IR (Fourier-transform infrared) spectroscopy provided information about the binding interaction of copper nanoparticles with the reducing agent, L-ascorbic acid. Potassium bromide which is a spectroscopic grade was used as background for IR analysis. 


\section{RESULTS AND DISCUSSION}

Figure 1 shows the XRD patterns of the prepared copper nanoparticles. The $2 \theta$ value of synthesized copper nanoparticles was observed at the peaks of $22.4,31.15,43.33,50.27$ and 74.18. This agrees with the standard value of face-centered cubic copper (ca. 38.48, 43.73, 51.39 and 73.42 representing $\mathrm{Cu}$ (111), (111), (200) and (220) planes of crystal face-centered cubic of copper (JCPDS-04-0836) (Langford and Wilson, 1978; Monshi et al., 2012).

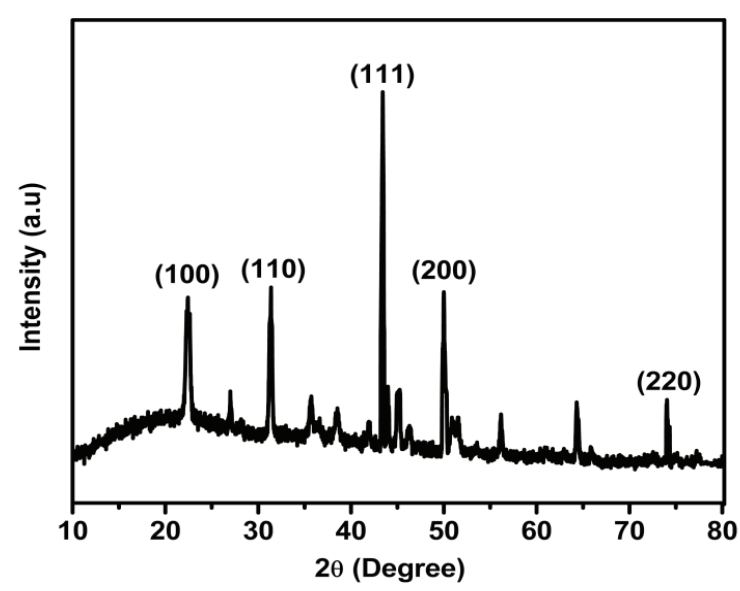

Figure 1 XRD Patterns of the prepared $\mathrm{Cu}$ nanoparticles measured with the scanning $2 \theta$ ranges from $10^{\circ}$ to $80^{\circ}$.

Some of the peaks which were not assigned to $\mathrm{Cu}$ nanoparticles were assigned for the minor characteristic peaks of $\mathrm{Cu}$ nanoparticles and the peaks of $\mathrm{Cu}_{2} \mathrm{O}$. Therefore, the XRD pattern reveals that the prepared nanoparticles are a mixture of metallic $\mathrm{Cu}$ and copper (I) oxide $\left(\mathrm{Cu}_{2} \mathrm{O}\right)$. The lattice parameter " $a$ " was calculated by using these profiles, and the average value of lattice parameter was found to be $3.60 \AA$, which is consistent with the previously reported literature value of $3.615 \AA$ (Otte, 1961).
The comparison of $2 \theta$ obtained in our experimental work with the values of $2 \theta$ described in JCPDS-040836 for copper nanoparticles are shown in Table 1. The peaks at 43.33, 50.29 and 74.18 correspond to the characteristic peak of the copper nanoparticles. The size of the as-synthesized copper nanoparticles was estimated from Debye Scherer equation (Langford and Wilson, 1978), and the result revealed that the copper nanoparticles had an average size of $50 \mathrm{~nm}$.

Figure 2 shows the FT-IR spectra of the pure L-ascorbic acid and the as-prepared copper nanoparticles. From the IR spectra of L-ascorbic acid, the peaks in the range of $3215-3520 \mathrm{~cm}^{-1}$ correspond to the different hydroxyl groups. The characteristic peak at $1766 \mathrm{~cm}^{-1}$ in the spectra of L-ascorbic acid is due to stretching vibrations of the $\mathrm{C}=\mathrm{O}$ of the five-membered lactone ring, and this band changed after coating on the nanoparticles (Sreeja et al., 2015).

Comparing with the IR spectra of the pure L-ascorbic acid and $\mathrm{Cu}$ nanoparticles stabilized with L-ascorbic acid, three major peaks have been disappeared from the later spectra, namely the $\mathrm{OH}$ stretching frequency in the range of 3219-3518 $\mathrm{cm}^{-1}$, the stretching frequency of the carbonyl group of the oxidized ester at1724 $\mathrm{cm}^{-1}$ and conjugated carbonyl group of the compound at $1629 \mathrm{~cm}^{-1}$.

.This indicated that the free ascorbic acid had chemisorptions on surface of copper nanoparticles to stabilize the as-prepared nanoparticles. Moreover, most of the peaks between 1000-1800 $\mathrm{cm}^{-1}$ of free L-ascorbic acid disappeared after stabilizing the $\mathrm{Cu}$ nanoparticles. This is due to the 
Table 1 Experimental and standard diffraction angles of copper nanoparticles.

\begin{tabular}{ccc}
\hline $\begin{array}{c}\text { Experimental results of } 2 \theta \\
\text { (degree) }\end{array}$ & $\begin{array}{c}\text { Standard diffraction } \\
\text { value of } 2 \theta \text { (degree) from } \\
\text { JCPDS-04-0836 [39,40] }\end{array}$ & $\begin{array}{c}\text { The value of hkl (plans) from } \\
\text { the value of } \\
\text { JCPDS-04-0836 }\end{array}$ \\
\hline 24.40 & - & $(100)$ \\
31.26 & 36.79 & $(110)$ \\
43.33 & 43.73 & $(111)$ \\
50.27 & 51.39 & $(200)$ \\
74.18 & 74.42 & $(220)$ \\
\hline
\end{tabular}

transformation of ascorbic acid to dehydroascorbic acid after reducing $\mathrm{Cu}^{2+}$ to $\mathrm{Cu}^{0}$. Hence, the characteristic peak such as the double bond, which is observed at around $1600 \mathrm{~cm}^{-1}$, corresponding to the free L-ascorbic acid disappeared during the reduction process.

The difference in the positions of peak results of free ascorbic acid and/or the change in the band width clearly indicated the formation of copper nanoparticles capped with ascorbic acid. According to Razium et al. (2014), the disappearance of other noticeable bands around $623 \mathrm{~cm}^{-1}, 588 \mathrm{~cm}^{-1}, 534 \mathrm{~cm}^{-1}$ and $480 \mathrm{~cm}^{-1}$ indicates the absence of the possible existence of copper oxides as $\mathrm{Cu}_{2} \mathrm{O}$ and $\mathrm{CuO}$ impurities.
Based on the experimental results, it is possible to suggest the advantage of using L-ascorbic acid as reductant and capping agent in the synthesis of copper nanoparticles at various experimental conditions of this work.

In general, the capping agents could prevent the agglomeration of small crystals and influence the structure and crystallinity of the as-synthesized copper nanoparticles. Therefore, we prepared the nanoparticles by changing the dynamics of the surfaces of the reducing and capping agent by controlling the reaction time, temperature and concentration.

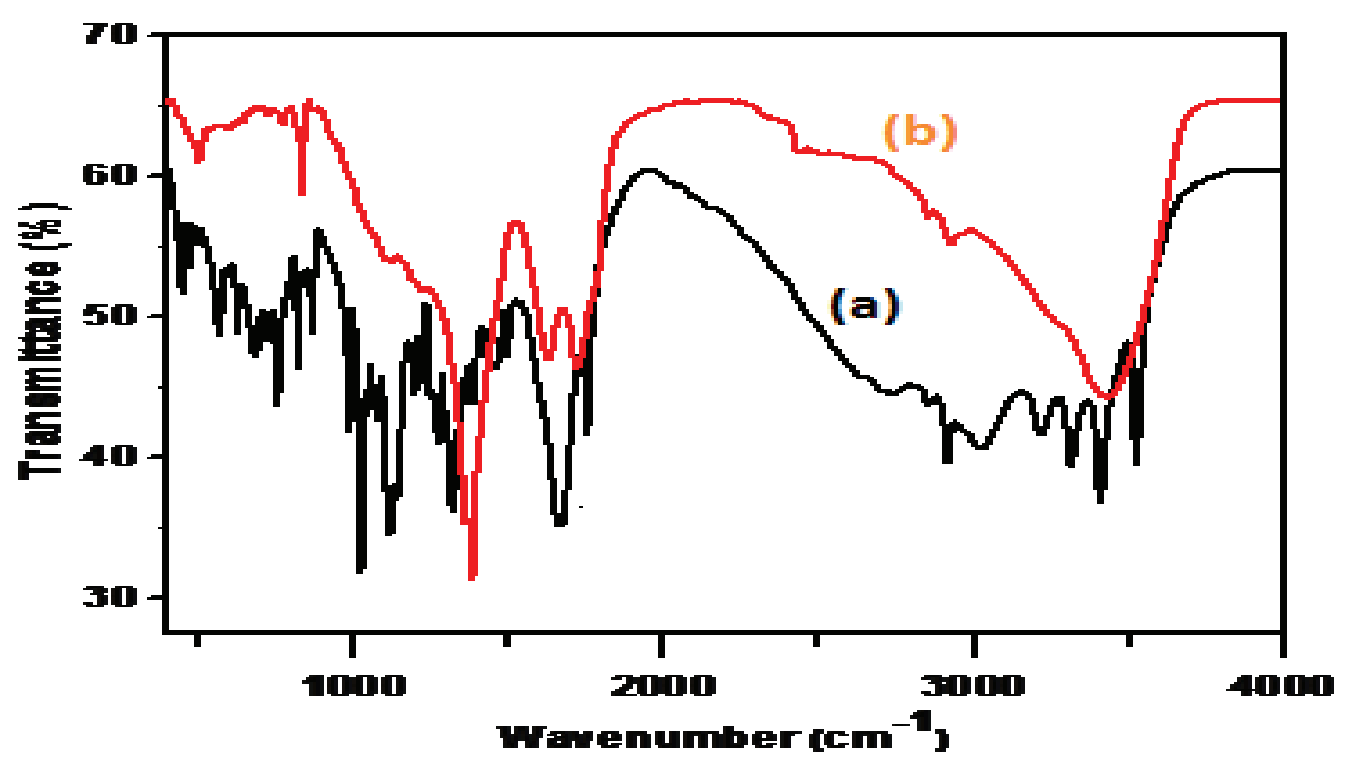

Figure 2 IR spectra of (a) pure L-ascorbic acid and (b) Cu nanoparticles stabilized with L-ascorbic acid 
When $\mathrm{CuCl}_{2} \cdot 2 \mathrm{H}_{2} \mathrm{O}$ and $L$-ascorbic acid solutions were mixed at a heating temperature of $80^{\circ} \mathrm{C}$ with frequent stirring, there was color change that could be used as an indication of the synthesis of copper nanoparticles or of the reduction of $\mathrm{Cu}^{+2}$ to $\mathrm{Cu}^{0}$ (Shikha et al., 2015). As it is shown in Figure 4, after $12 \mathrm{hrs}$ of the reaction time, the color gets more intense. This phenomenon could occur due to the consumption of higher concentration of $L$-ascorbic acid to form the copper nanoparticles. As the concentration of $L$-ascorbic acid increases, the number of dispersed copper nanoparticles will increase resulting in a decreasing agglomeration of the particles (Huixiao et al., 2012).

As noted above, the formation process of $\mathrm{Cu}$ nanoparticles can be supported by the color change of the reaction mixture and UV-vis spectra. Thus, the optical properties of the prepared copper nanoparticles were examined using the data obtained from UV-Vis absorption measurement of the as-synthesized copper nanoparticles in distilled water. Figure 3 shows the UV-Visible spectra of the precursor salt, ascorbic acid and the synthesized copper nanoparticles. Moreover, the effect of reaction time and of temperature on the formation of $\mathrm{Cu}$ nanoparticles indicated by color changes is explained in Figure 4 and 5, respectively. The color change was due to Surface Plasmon Resonance (SPR).

Nano-sized particles exhibit unique optical properties having an exponential-decay Mie scattering profile with decreasing photon energy (Chen and Sommers, 2001). The collective oscillations of conduction electrons at the surface of nano-sized metal particles absorb visible electromagnetic waves, which is known as Surface Plasmon Resonance (SPR) (Dang et al., 2011).
Such phenomenon of SPR of metal nanoparticles is largely size dependent. But the exact position and shape of the Plasmon absorption peaks may depend on several factors including size of particle, type of solvent, capping agent, the particle morphology, dielectric functions of the metal and the surrounding medium as well as surfaceabsorbed species (George et al., 2007).

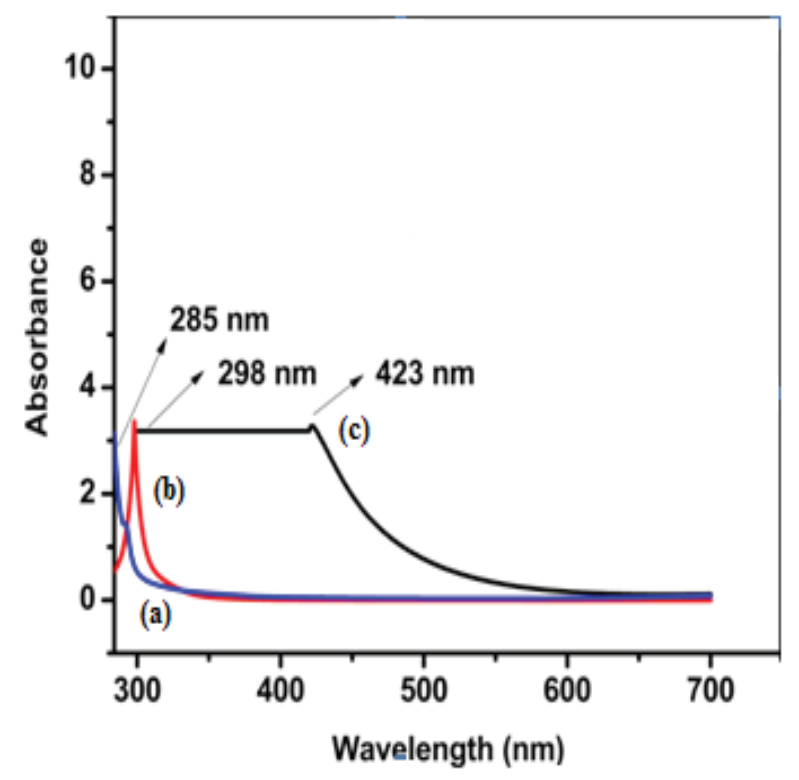

Figure 3 UV-Visible spectra of precursor salt (a), ascorbic acid (b) and $\mathrm{Cu}$ NPs (c).

As Figure 3 above shows, the absorption edge of the as-prepared copper nanoparticles was determined at around $423 \mathrm{~nm}$, which is closer to the literature value $(450 \mathrm{~nm})$ reported for the copper nanoparticles (Arunachalam and Kannappan, 2013). This result, thus, confirms the formation of copper nanoparticles.

In this study, it was realized that the reaction time is one of other important parameters in the synthesis of copper nanoparticles. As time of reaction increases, the formations of copper nanoparticles will increase since the reactants have ample time for completion. In other words, 
when the reaction time increases, the copper nanoparticles synthesized by chemical reduction method using L-ascorbic acid as protective agent lead to the formation of well-defined nanoparticles (Dang et al., 2011). Therefore, it is possible to understand that copper nanoparticles could be best synthesized at around 12 hours of reaction time. That is, the color change observation shown in Figure 4 indicates that 12 hours reaction time is the suitable reaction condition for the successful preparation of copper nanoparticles.

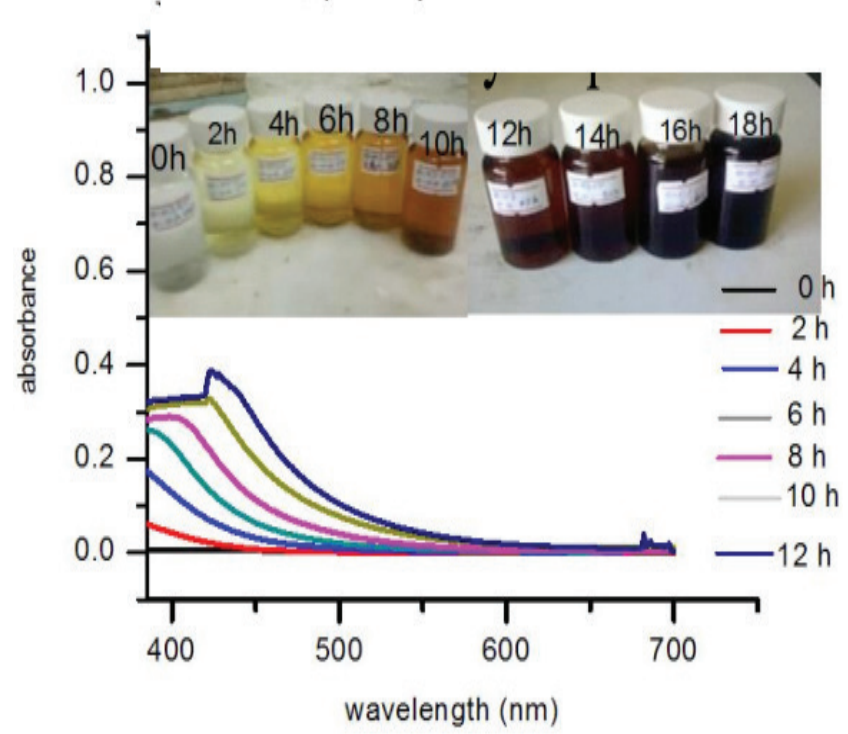

Figure 4 UV-VIS spectra of $\mathrm{Cu}$ nanoparticles prepared at different intervals of reaction time with its corresponding color change observed.

Reaction temperature is also another important reaction parameter in the synthesis of copper nanoparticles. To elucidate the effect of temperature, $3 \mathrm{mM}$ of copper chloride dihydrate solution and $4 \mathrm{mM}$ L-ascorbic acid solution were heated at different temperature $\left(55^{\circ} \mathrm{C}, 65^{\circ} \mathrm{C}, 75^{\circ} \mathrm{C}\right.$ and $90^{\circ} \mathrm{C}$ ). The result revealed that temperature below $65^{\circ} \mathrm{C}$ is not suitable for the complete formation of copper nanoparticles. In addition, reaction temperature above $90^{\circ} \mathrm{C}$ was also found to be inconvenient as characteristic color and UVVis absorption spectrum of copper nanoparticles were not observed. Therefore, it is difficult to control the size of the particles at these levels of temperature, and this may result in agglomeration of particles. This implies that the suitable range of thermal temperature for the formation of copper nanoparticles is between $70^{\circ} \mathrm{C}$ and $90^{\circ} \mathrm{C}$ at appropriate concentration (Huixiao et al., 2012). Figure 5 shows UV-Vis absorbance spectra of the as-synthesized copper nanoparticles at different ranges of temperature.

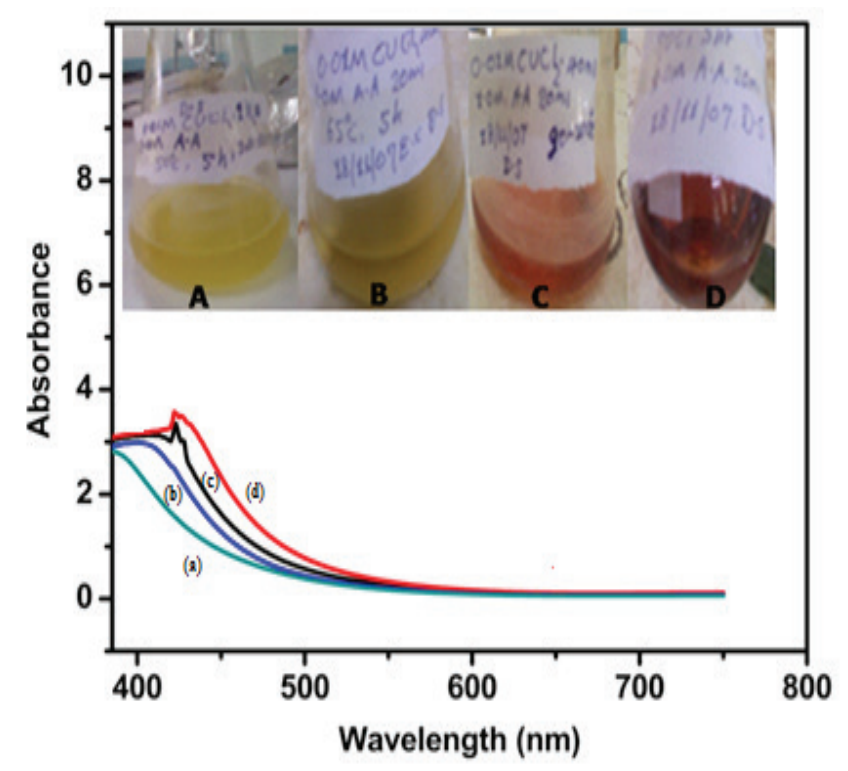

Figure 5 UV-VIS spectra of $\mathrm{Cu}$ nanoparticles prepared at (a) $55{ }^{\circ} \mathrm{C}$, (b) $65{ }^{\circ} \mathrm{C}$, (c) $75{ }^{\circ} \mathrm{C}$ and (d) $90{ }^{\circ} \mathrm{C}$ with its corresponding color change

In the formation mechanism of $\mathrm{Cu}^{2+}$, the first step, $\mathrm{Cu}^{2+}$ is reduced to $\mathrm{Cu}^{0}$ by the help of the reducing agent, L-ascorbic acid, so as to form a nucleus. Then the nuclei were stabilized by the capping agent, L-ascorbic acid, for the growth of $\mathrm{Cu}$ nanoparticles. $\mathrm{Cu}^{2+}$ ions were initially transformed to $\mathrm{Cu}(\mathrm{OH})_{2}$ as precursor, and then $\mathrm{Cu}(\mathrm{OH})_{2}$ was reduced to $\mathrm{Cu}_{2} \mathrm{O}$ using $\mathrm{L}$-ascorbic acid. $\mathrm{Cu}_{2} \mathrm{O}$ was finally reduced to $\mathrm{Cu}$ nanoparticles. The reduction process can be rationalized using the equations shown below. 
<smiles>CC(C)(C)[O+][O+]</smiles>

L-Ascorbic Acid

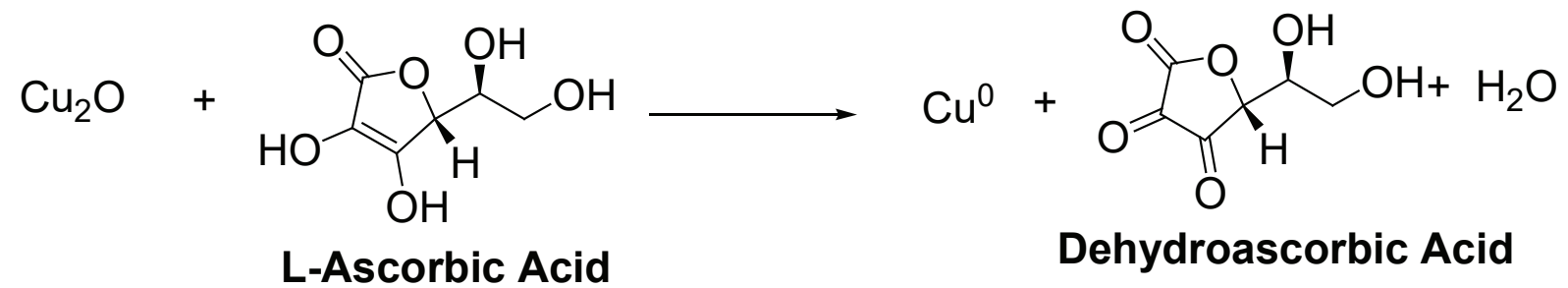

Dehydroascorbic Acid

\section{Dehydroascorbic Acid}

The antibacterial activity of the prepared copper nanoparticles was investigated against both grampositive and gram-negative bacteria.The growth inhibition of the tested bacterial strains is also indicated in Table 2 and 3.

The results in Table 2 shows that copper nanoparticles formed at a concentration of $3 \mathrm{mM}$ cupric chloride dihydrate salt solution and that 4 $\mathrm{mM}$ L-ascorbic acid exhibited an excellent zone of growth inhibition of $16.83 \pm 0.42 \mathrm{~mm}$ for gramnegative bacteria while Table 3 reveals the zone of growth inhibition of $15.50 \pm 0.89 \mathrm{~mm}$ for grampositive bacteria.

Table 2 The antibacterial activity of the prepared copper nanoparticles: Zone of inhibition (mm) against $E$. coli and P. aeruginosa.

Zone of inhibition (mm)

Concentration, (mM) Bacteria

(the ratio of salt to E. coli $(\mathrm{G}-\mathrm{Ve})^{*} \quad$ P. aeruginosa $(\mathrm{G}-\mathrm{Ve})^{*}$

AAH)

Mean \pm SD $\quad$ Mean \pm SD

\begin{tabular}{|c|c|c|c|c|c|c|c|c|}
\hline $2 \mathrm{CuCl}_{2} \cdot 2 \mathrm{H}_{2} \mathrm{O}$ & 8.2 & 9.3 & 8.5 & $8.67 \pm 0.57$ & 8.8 & 8.7 & 9.2 & $8.90 \pm 0.26$ \\
\hline $4 \mathrm{AAH}$ & 12.4 & 13.3 & 12.9 & $12.87 \pm 0,47$ & 13.4 & 14.5 & 13.8 & $13.90 \pm 0.55$ \\
\hline $\begin{array}{l}2 \\
\text { mMsalt:4mMAAH }\end{array}$ & 13.3 & 14.4 & 13.9 & $13.83 \pm 0.55$ & 13.5 & 12.7 & 13.3 & $13.17 \pm 0.66$ \\
\hline 3mMsalt:4mMAAH & 17.5 & 16.9 & 18.4 & $17.60 \pm 0.75$ & 16.7 & 16.5 & 17.3 & $16.83 \pm 0.42$ \\
\hline Tetracycline & 19.6 & 20.4 & 19.8 & $19.93 \pm 0.42$ & 16.9 & 17.4 & 17.5 & $17.27 \pm 0.18$ \\
\hline Sterile distilled $\mathrm{H}_{2} \mathrm{O}$ & 0 & 0 & 0 & $0 \pm 0$ & 0 & 0 & 0 & $0 \pm 0$ \\
\hline
\end{tabular}


Table 3 The antibacterial activity of the prepared copper nanoparticles: Zone of inhibition (mm) against $S$. aureus and $P$. pyogenes.

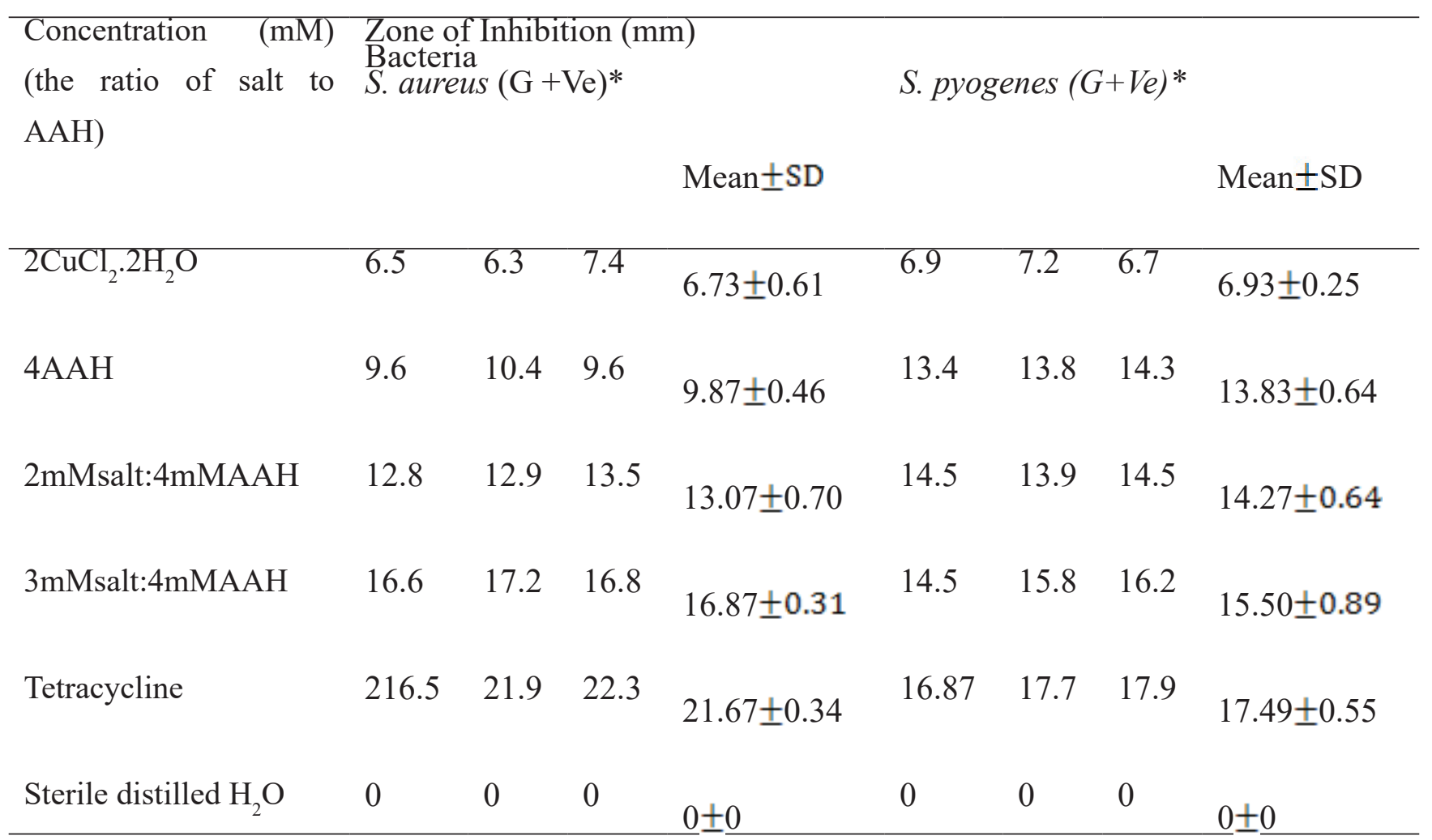

$\mathrm{n}=3 ; *$ triplicate measurement

The antibacterial activity study revealed that the concentration of copper nanoparticles has a linear correlation with zone of inhibition growth, i.e. as the concentration of copper nanoparticles increases, the zone of inhibition also increases (Rajesh et al., 2010). This present antibacterial activity investigation showed that the prepared copper nanoparticles exhibited almost similar zone of inhibition growth towards the Gram-positive and Gram-negative tested bacteria strains (Table 2 and 3).

The antibacterial mechanism of metal nanoparticles is not still known clearly. However, it has been reported that when metal nanoparticles are attached to the surface of the cell membrane, the composition of cell wall varies rapidly affecting the wall permeability, the respiratory function and DNA of which it tends to lose its ability to replicate (Pal et al., 2007). The mechanism by which the nanoparticles were able to penetrate the cell wall was due to changes in membrane morphology that significantly increases permeability and affects proper transport through the plasma membrane leaving the bacterial cells incapable of properly regulating transport through the plasma membrane and resulting in cell death (Ekezie et al., 2017).

Furthermore, the enhanced activity of the synthesized nanoparticles could be their improved characteristics and morphological properties of nanoscale materials in terms of specificity and better manipulation, increased 
surface area available for interactions, which enhances bactericidal effect than the large sized particles and thus, they impart cytotoxicity to the microorganisms (Ekezie et al., 2017).

The bactericidal effect of metal nanoparticles has been attributed to their size and high surface to volume ratio, which allows them to interact with microbial membranes and is not merely due to the release of metal ions in solution (Mokae et al., 2017). According to Deryabin et al., the mechanism of antibacterial activity of $\mathrm{Cu}$ nanoparticles could be manifested by the disruption of energy metabolism in the target bacterial cells, which causes fast-developing inhibition, resulting in the decrease in transmembrane electrochemical potential of the cytoplasmic membranes (Deryabin et al., 2017).

\section{CONCLUSIONS}

A simple, economical, environmentally benign and green as well as temperature controlled synthesis method has been developed for the preparation of copper nanoparticles. The optical properties and crystallinity of the as-synthesized copper nanoparticles were characterized by UVVis Spectrophotometer and XRD. The binding effect of L-ascorbic acid was studied by FT-IR spectroscopy. The XRD patterns showed that the structure of the synthesized copper nanoparticles are FCC and their size was calculated using DebbyScherer equation, and the size was found to be around $50 \mathrm{~nm}$. The UV-Vis absorption spectra show that as the concentration of L-ascorbic acid increases, the formation of copper nanoparticles will increase. The IR stretching frequencies of the hydroxyl group in the range of 3219-3518 $\mathrm{cm}^{-1}$ and carbonyl groups at $1724 \mathrm{~cm}^{-1}$ and $1629 \mathrm{~cm}^{-1}$ of the free ascorbic acid in the synthesized nanoparticles disappeared which indicated that the free ascorbic acid reacted with the cupric chloride dihydrate solution in order to afford the copper nanoparticles. The characterization results of the aforementioned techniques suggested that the copper nanoparticles were prepared successfully. The method will be used as a competitive alternative technique for the preparation of other related nanoparticles. In addition, the antibacterial activities of copper nanoparticles at different concentrations exhibited excellent antibacterial activity against the tested Gram-positive and Gram-negative bacteria. The result also showed the zone of inhibition which depends on the concentration of nanoparticles.

\section{ACKNOWLEDGEMENTS}

The authors are thankful to Bahir Dar University, Bahir Dar, Ethiopia for the financial support and to Amhara regional laboratory for the supply of the bacterial strains and for the technical support during the assay of the antibacterial activity of the as-synthesized copper nanoparticles.

\section{REFERENCES}

Appu, M and Muthukrishnan, S. (2015). Green synthesis of copper-chitosan nanoparticles and study of its antibacterial activity. Journal of Nanomedicine and Nanotechnology 6(1): $1-5$.

Arunachalam, D.K and Kannappan, G. (2013). Synthesis of copper precursor, copper and its oxide nanoparticles by green chemical reduction method and its antimicrobial activity. Journal of Applied Pharmaceutical Science 3(5): 16-21. 
Ayesha, K., Audil, R., Rafia, Y and Ren, C.A. (2015). Chemical reduction approach to the synthesis of copper nanoparticles. International Nano Letters 10: 1-6.

Chen, S.W and Sommers, J.M. (2001). Effects of copper salts and reducing agents on characteristics of nanoparticles. The Journal of Physical Chemistry B 105: 8816-8820.

Dang, T.M., Le, T.T., Blanc, E.F and Dang, M.C. (2011). Synthesis and optical properties of copper nanoparticles prepared by a chemical reduction method. Advances in Natural Sciences: Nanoscience and Nanotechnology 2(1): 1- 6.

Dang, T.M., Le, T.T., Fribourg-Blance, E and Dang, M.C. (2011). Influence of surfactant on the preparation of silver nano particles by polyl method", Advances in Natural Sciences: Nanoscience and Nanotechnology 359: 19 -23 .

Deryabin, D.G., Aleshina, E.S., Vasilchenko, A.S., Deryabina, T.D., Efremova, L.V., Karimov, I.F and Korolevskay, L.B. (2013). Investigation of copper nanoparticles antibacterial mechanisms tested by luminescent Escherichia coli strains. Nanotechnologies in Russia 8 (56): $402-408$.

Eastman, J.A., Choi, S.U., Li, S., Yu, W and Thompson, L.J. (2001). Anomalosly increased effective thermal conductivity of ethylyne glycol based nano fluids containing copper nanoparticles. Applied Physics Letters 78: 718-720.

Ekezie, F.C., Suneetha, W.J., Maheswari, K.U., Kumari, B.A and Prasad, T.N. (2017). Green synthesis of copper nanoparticles using Momordica charantia fruit extracts and evaluation of their anti-microbial efficacy. International Journal of Current Microbiology and Applied Sciences 6(4): 99-109.

Espinel-Ingroff, A.V and Pfaller, M.A. (2007). Manual of clinical microbiology, $9^{\text {th }}$ Edn. ASM press, Washington 1972-1973.

George, H.C., Jing, Z., Erin, M.H., George, C.S and Richard, P.V. (2007). Plasmonic properties of copper nanoparticles fabricated by nanosphere lithography. Nano Letters 7 (7): 1947-1952.

Gopinath, M, Subbaiya, R, Masilamani, S.M and Suresh, D. (2014). Synthesis of copper nanoparticles from Nerium oleander Leaf aqueous extract and its antibacterial ctivity. International Journal of Current Microbiology and Applied Sciences 3 (9): 814-818.

Heera, P, Shanmugam, S and Ramachandran, J. (2015). Green synthesis of copper nanoparticle using Gymnema sylvestre by different solvent extract. International Journal of Current Research and Academic Review 3(10): 268-275.

Huixiao, H, Hong, H, Rui, W, Xiaojun, L and Guizhen, Z. (2012). Controlled synthesis and characterization of noble metal nanoparticles. Soft Nanoscience Letters 2: 34-40.

Ipsa, S and Nayak, P.L. (2013). Synthesis of copper canoparticles using Syzygium aromaticum (Cloves) aqueous extract by using green chemistry. World Journal of Nano Science Technology 2(1):14-27.

Kathad, U and Gajera, H.P. (2014). Synthesis of copper nanoparticles by two different methods and size comparison. International Journal of Pharmacy and Biological Sciences 5(3): 533 - 540. 
Kruis, F.E., Fissan, H and Peled, A. (1998). Synthesis of nanoparticle in the gas phases for electronic, optical and magnetic applications: A review. Journal of Aerosol Science 29: 511-535.

Langford, J.I and Wilson, A.J. (1978). "Scherer after sixty years: a survey and some new results in the determination of crystallite size". Journal of Applied Crystallography 11(2): $102-113$.

Liu, Q, Takehiro, Y, Kensuke, K and Masazumi, O. (2012). Preparation of $\mathrm{Cu}$ nanoparticles with ascorbic acid by aqueous solution reduction method. Transactions of Nonferrous Metals Society of China 22: 2198-2203.

Mokae, F.B., Rui, W.M and Richard, M.M. (2017). Facile method for the synthesis of copper nanoparticles supported on the organoclay material. Journal of Biomaterials and Nanobiotechnology 17 (8): 144-158.

Monshi, M, Monshi, M.R and Foroughi, R. (2012). "Modified Scherer equation to estimate more accurately nano-crystallite size using XRD," World Journal of Nano Science and Engineering 2(3): 154 -160.

Nadejda, N.B.,Oksana, A.S., Ekaterina, I.S., Olga, Y.T., Andrey, M.Z., Rimma, K.C., Aleksey, A.K and Evgeny, G.G. (2017). Synthesis of copper nanoparticles stabilized with cetylpyridinium chloridemicelles. Advanced Materials Letters 8 (4): 404-409.

Umer, A., Naveed, S., Ramzan, N., Rafique, M.S and Imran, M. (2014). A green method for the synthesis of copper nanoparticles using L-ascorbic acid. Revista Matéria 19 (3): $197-203$

Otte,H.M.(1961).Latticeparameterdeterminations with an X-Ray Spectrogoniometer by the Debye-Scherrer method and the effect of specimen condition. Journal of Applied Physics 32: 1536-1545.

Pal, S, Tak, Y.K and Song J.M. (2007). Does the antibacterial activity of silver nanoparticles depend on the shape of the nanoparticle? A study of the gram-negative bacterium Escherichia coli. Applied and Environmental Microbiology 73: 17121720 .

Rajesh, K, Harsha, R, Mohammed, G.A., Hareesh, A.R., Thammanna Gowda, S.S., Dinesha, R.B., Satish, K and Irfan, A.M. (2010). Antimicrobial activity of ethanol extract of leaf and flower of Spathodea campanulata P. Beauv. Research Journal of Pharmaceutical, Biological and Chemical Sciences 1(3): 691 -698.

Razium, A.S., Ayman, N, Sirajuddin, S, Tufail, H.S., Nazar, H.K., Mohammad, R. S and Keith, R. (2014). Catalytic reductive degradation of methyl orange using air resilient copper nanostructures. Journal of Nanomaterials 2015: 1-12.

Shikha, J, Niharika, N and Vijay, D. (2015). Synthesis and characterization of highly efficient copper nanoparticles and their catalytic application in oxidative kinetic study. Advances in Applied Science Research 6(6): 171-180.

Shobha, G, Vinutha, $M$ and Ananda, S. (2014). Biological synthesis of copper nanoparticles and its impact - a Review. International Journal of Pharmaceutical Science Invention 3(8): 28-38.

Sreeja, V, Jayaprabha, K.N and Joy, P.A. (2015). Water-dispersible ascorbic-acid-coated magnetite nanoparticles for contrast enhancement in MRI.Applied Nanosciences 5 (4): 435-441.

Sudhir, S, Avinash, P.I., Aniket, G and Mahendra, R. (2015). Green synthesis of copper nanoparticles by Citrus medica Linn. (Idilimbu) juice and its antimicrobial activity. World Journal of Microbiology and Biotechnology 31: 865-873.

Vasudeo, K., Sampat, S and Pramod, K. (2015). Biosynthesis of copper nanoparticles using aqueous extract of Eucalyptus Sp. plant leaves. Current Science 109 (2): 255-257. 